\title{
Traduire
}

Une autre perspective sur r tr traduction

Revue française de la traduction

$226 \mid 2012$

Face au miroir

\section{«La vie est brève, le désir sans fin »}

\section{Bernhard Lorenz}

\section{(2) OpenEdition}

Journals

Édition électronique

URL : http://journals.openedition.org/traduire/160

DOI : 10.4000/traduire.160

ISSN : 2272-9992

Éditeur

Société française des traducteurs

Édition imprimée

Date de publication : 1 janvier 2012

Pagination : 89-92

ISBN : 039-773X

ISSN : 0395-773X

Référence électronique

Bernhard Lorenz, « «La vie est brève, le désir sans fin » », Traduire [En ligne], 226 | 2012, mis en ligne le 03 février 2014, consulté le 11 octobre 2020. URL : http://journals.openedition.org/traduire/160 ; DOI : https://doi.org/10.4000/traduire.160

Ce document a été généré automatiquement le 11 octobre 2020 


\title{
« La vie est brève, le désir sans fin »
}

\author{
Bernhard Lorenz
}

1 Le titre du livre de Patrick Lapeyre a récemment capté mon attention dans une librairie, le bandeau « Prix Fémina 2010 » me faisant signe et je ne me suis pas fait prier pour soutenir l'économie éditoriale française.

2 Je vous le dis d'entrée de jeu, à mon goût, le roman n'a pas été à la hauteur de mes espérances, mais je ne l'ai pas lâché en cours de route, attaché que j'étais, mine de rien, à un des personnages centraux du livre: Louis Blériot-Ringuet, 41 ans et traducteur fauché. "Il s'est mis traducteur free-lance il y a trois ou quatre ans - il traduit de l'anglais plutôt que de continuer à être pressuré par des officines privées qui le payaient au lance-pierre. $»($ p. 45). Ce pauvre homme, aux prises avec le démon de midi, et manquant de travail et par conséquent d'argent, passe une fois par mois environ chez un riche ami, qui lui prête de l'argent (toute- fois, il est marié à une femme qui gagne correctement sa vie pour un foyer sans enfants). "Ce sont encore mes soucis d'argent, s'excuse-t-il - sachant qu'on ne manquera pas de le croire - je n'ai plus un sou, je suis interdit bancaire" ... (p. 154). Donc, oyez braves gratte-clavier, il vaut mieux avoir un compagnon de vie financièrement à l'aise.

3 Pour faire bouillir la marmite,

il est obligé d'accepter à peu près tout et n'importe quoi pour faire tourner son petit commerce, et traduit aussi bien des articles scientifiques, des notices pharmaceutiques que des modes d'emploi d'appareils ménagers. Les jours fastes, il fait quelques piges pour des congrès médicaux, mais la plupart du temps il reste chez lui et se contente de ce qu'on lui propose. Et quand on ne lui propose rien, il n'a en général d'autre recours que de faire appel à la générosité de son entourage. Ce genre d'expédient expliquant, en partie, l'évident déficit d'image dont il souffre auprès de sa femme et de ses parents... (p. 45-46).

$\mathrm{Au}$ début du livre, Louis retrouve une ancienne maîtresse (anglaise) un peu fantasque, fragile et éprise de liberté. Elle était partie deux ans auparavant pour vivre (entre autres) avec Murphy, un trader américain, et souhaite reprendre le fil de ses amours torrides avec Louis. Le livre sera jalonné de départs et de retrouvailles qui vont brûler toute la cervelle du pauvre traducteur (c'est moi qui le dit) ainsi que celles du financier (les prémisses de la crise?). 
5 Au cours du livre, on va rarement trouver Louis dans son bureau, une "pièce de six mètres sur cinq, situé à l'étage, ou à défaut d'être très concerné par son travail, il peut au moins réfléchir calmement, spacieusement »(p. 45), puisqu'il va, dès que sa femme est partie en voyage d'affaires - passer ses après-midis et nuits chez sa marquise. Il pourrait accompagner sa femme, à plusieurs reprises elle l'invite, mais il prétexte toujours des charrettes par-ci, des pages à traduire par là. De fait, sa vie tourne autour de son amante, chez qui et avec qui il passe un maximum de son temps.

Il passe une partie de la journée dans un état d'anxiété flottante, la tête plongée dans son dictionnaire ("sexe » et "sécateur ", découvre-t-il par hasard, ont la même racine : «secare ») puis tape une dizaine de lignes de sa traduction sur les troubles lymphatiques..... » (p. 100).

Quant à la vitesse de son travail, son « rendement» nous en avons un indice page 159: «... un peu avant six heures - il a traduit deux cent cinquante mots - Blériot sort de l'hôtel... » Il aura mis 3 heures pour ce texte!

7 Vers la fin du livre, quand sa femme sera partie et que son amour fou pour sa maitresse aura tourné pour la énième fois en eau de boudin, il retrouve un peu de l'assiduité que je connais moi de mon métier de traduction:

Il traduit à raison de trois à quatre heures par jour une communication américaine sur certaines dégénérescences de l'appareil neurovégétatif - on croirait que c'est écrit pour lui - remplie de termes aussi ésotériques que les procédés de neurochimiotactisme ou les microtubules colloïdaux, qu'il aligne tranquillement sans se poser de questions. Pour se donner un peu de cœur à l'ouvrage et stimuler son propre système moteur, il fume et boit à peu près sans discontinuer tout en écoutant en fond sonore Duke Ellington et son grand orchestre. (p. 308).

Notez donc, chers lecteurs, que contrairement aux détectives, le traducteur ne se pose pas de questions mais qu'il boit et fume beaucoup.

... Au milieu de cette vie terne, purgée des passions et disciplinée par le travail, il lui arrive de se dire qu'il était né pour vivre seul et traduire des pages d'anglais... (p. 308).

9 Toutefois, cela ne l'empêche pas de peiner sur une page. La noradrénaline, continue-t-il à taper, a notamment ... Ensuite, malgré ses efforts, il n'arrête pas de piquer du nez sur sa page de traduction comme s'il était repris par sa narcolepsie... (p. 342)

J'ai bien l'impression que Patrick Lapeyre (hypokhâgne, professeur de lycée) connaît un peu la traduction; toutefois son personnage, malgré son statut de free-lance, n'est guère recommandable professionnellement parlant et ne semble pas être très ouvert au monde en dehors de la traduction médicale, il se sent même quasiment inculte face à sa maîtresse théâtreuse :

Je n'ai jamais vu «La Mouette », ni « La Jeune Fille Violaine », lui avoue-t-il. ... Je passe ma vie à lire et à traduire de la littérature médicale. Alors, à par $t$ ça, j'ai dû lire cette année, en tout et pour tout, un roman de SF, deux romans policiers, les Mémoires de Churchill, et, sur les recommandations d'un ami, j'ai commencé à lire les Essais de théodicée de Leibniz. Je crois que c'est à peu près tout. (p. 148-149).

11 Morale moralisante de l'histoire : un traducteur professionnel passionné par son travail et bénéficiant d'un agenda chargé n'aura ni le temps, ni l'envie de mener une double vie - mais un tel traducteur n'est pas suffisamment «sexy " pour être le héros d'un roman! 


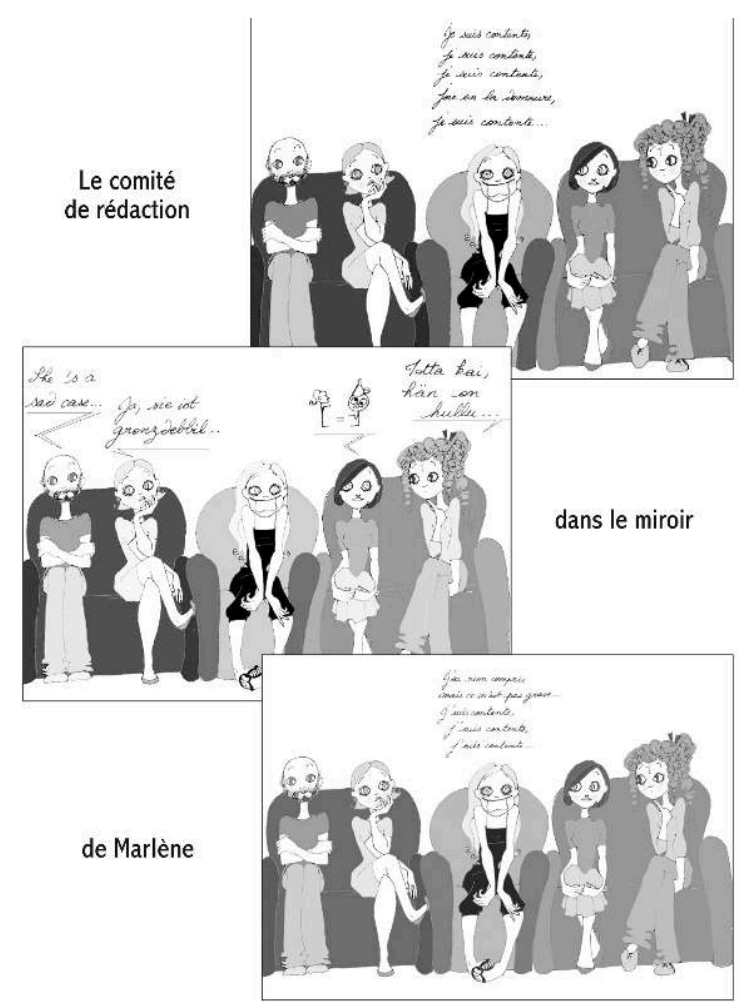

Illustration : Marlène Junius, http://alotoftralala.over-blog.com

\section{AUTEUR}

BERNHARD LORENZ

lorenztradfin@gmail.com 